\title{
Dental care of children with leukaemia- an overview
}

\begin{abstract}
The word leukemia derived from a Greek Leukos means white and aima - blood ; it is a cancer of the blood or bone marrow characterized by an abnormal increase of blood cells, usually leukocytes. Approximately 2,56,000 children and adults around the world developed some form of leukemia and about ninety percent of all leukemias are diagnosed in adults. No single known cause for all of the different types of leukemia exists. Some people have a genetic predisposition towards developing leukemias and also chromosomal abnormalities. Based on the type of blood cell is affected it can be lymphocytic leukemias and myelogenous leukemias; based on pathology it can be acute and chronic type of leukemias. Musoal pallor, petichiae, ecchymoses, bleeding ulceration, gingival enlargement, trismus, are the initial oral manifestations of leukemias. Diagnosis is usually based on repeated complete blood counts and bone marrow examination following symptoms observed. Most forms of leukemia treated with pharmaceutical medications typically combined into a multidrug chemotherapy regimens. Any extractions should be done in the hospital under the care of physician in charge and in consultation with the haematologist. Inferior alveolar nerve block should never be used. Superficial injections may be permissible. Removal of superficial caries and retention of a filling which seals the cavity is advisable. Treatment should be as short as possible. To keep the gingiva healthy instruction on tooth brushing is mandatory. Only if the patient himself is very anxious for treatment of malocclusion should be considered. This article discuss along with probable etiological factors, clinical features, diagnosis, treatment options are discussed.
\end{abstract}

Keywords: children, dental care, oral health, leukemia
Volume 4 Issue 5 - 2016

\author{
Saikrishna Degala,' Nirmala SVSG ${ }^{2}$ \\ 'Department of Oral \& Maxillofacial Surgery, JSS Dental College, \\ India \\ ${ }^{2}$ Department of Pedodontics \& preventive Dentistry, Narayana \\ Dental College, India
}

\begin{abstract}
Correspondence: Nirmala SVSG, Department of Pedodontics \& preventive Dentistry, Narayana Dental College, Chintharaddy palem, Nellore, Andhra Pradesh, India,

Email nimskrishna2007@gmail.com
\end{abstract}

Received: May 14, 2016 | Published: June 15, 2016

\section{Introduction}

Leukemia is a fatal disease in which the production of white blood cells is out of control and many immature and abnormal types appear in the blood. The most commonly affected white cells are lymphocytes, myelocytes or monocytes but the resulting immature cells may be difficult to identify. It is usual to divide leukemia's into acute and chronic types, the former being cases terminating within a few months of onset, and the later lasting one or more years, assuming lack of treatment. Modern therapy which has extended the life expectancy of some extent has made this division rather arbitrary in some cases. There is a particularly high incidence of the disease among children with mongolism. ${ }^{1}$

In India, $25-40 \%$ of the children suffering with leukemia and 60 $85 \%$ children are more prone for Acute Lymphoblastic Leukemia (ALL). ${ }^{2}$

\section{Classification'}

1. Based on the duration, leukemia can be two types as

- Acute and Chronic type

2. Based on the cell involved;

- Myeloid, Lymphoid, or Monocytic

\section{Acute Leukemia}

Onset in the across type is most common in the preschool age group and the first sign may be an upper respiratory infection or oral ulceration. The child is febrile, weak and listless and more prostrated than would be expected from such a condition. Rapidly developing anemia causes pallor and there is a tendency to hemorrhage due to a fall in the platelet level. These symptoms are produced by the invasion and displacement of the bone marrow by leukemia tissue, resulting in a decrease in output of red blood cells, platelets and normal white cells. The red cell count may be as low as one million. The leukemic tissue also causes enlargement of lymph nodes, spleen, kidney, liver and other organs by invasion and replacement of the normal tissue, resulting in symptoms of deficient function of these organs. Internal hemorrhage at various sites is common and death is often due to intracranial hemorrhage. There is usually a raised white cell count of 15,000 to 30,000 but in a number of cases it is lower than normal. Spontaneous remissions occur lasting only a few months, but sometimes there is a change from the acute to a more sub - acute or chronic course.

\section{Chronic leukemia}

The onset of this type of leukemia is more insidious than in the acute variety and occurs in rather older children. Anemia and its symptoms of restlessness, pallor and dyspnoea or the discomfort of an enlarged spleen may be the first sign. These are progressive and there may be a slight intermittent fever. Though a high platelet count occurs in few cases, it is usually low and there is therefore a tendency to prolonged bleeding and petechiae. The white cells count is usually far higher than in the acute type of leukemia and may be 2,00,000 per $\mathrm{mm} 3$ or more with many immature types. Spontaneous remission may occur and may last for few months or years. Bone lesions occur in the majority of leukemia patients and may appear as osteosclerotic. Acute Leukemia is rapidly progressive without treatment, and the fatal termination may be due to infection or haemorrhage. With therapy, however, life may be due prolonged and in the chronic case this may be several years. Treatment is primarily by chemotherapy and several groups of drugs may be used. The corticosteroids produce a dramatic remission which may last for some weeks to months. They are given in courses of atleast six weeks duration. Antimetabolite drugs, particularly aminopterin and methotrexate are valuable and probably interfere with the use of folic acid for which the leukemic cells have a greater demand than do normal cells. 6-mercaptopurine, a purine 
analogue, is another drug frequently used. The degree of remission obtained from each course of a drug gradually becomes less, and the therapy is then changed to another. Many of these children are on two or more concurrently. Irradiation can be of value in chronic cases when the total body or the spleen is exposed, or in the relief of the bone pain which is a feature of this disease. In the former case the dosage is of the order of 15 to 20 roentgens for several successive days and in the latter, 50 to 100 roentgens locally on alternate days. The prolonged use of antibiotics for the control or prevention of infection is not recommended in view of the dangers of the infection by resistant organisms, but short intensive courses are desirable. The parents of such child receive education on his care and efforts are made to enable him lead a normal life, without over protection or emotionalism. He lives at home and attends normal school whenever possible, since the aim is a happy sensible environment. Only when the family is quite unsuitable is hospitalization considered except for real medical care. ${ }^{1}$

Lymphoblasic leukemia: B lymphocytes are most commonly involved which are infection fighting immune system cells.

Myelogenous leukemia: The cancerous alteration proceeds in a type of marrow cell that normally drives on to form red blood cell, some other types of white cell, platelets.

\section{Other Classification Delivers A Total of 4 Main Categories}

i. Acute Lymphoblastic Leukemia (ALL): It is seen in children and adults particularly above 65 years. It is treated with chemotherapy and radiation and survival rate is $85 \%$ in children and whereas in adults by $50 \% .^{3}$

ii. Acute Myelogenous Leukemia (AML): Adults and Men are commonly involved than children and women, chemotherapy is the treatment of choice. ${ }^{4}$

iii. Chronic myelogenous leukemia (CML): Adults are more commonly involved than children. It can be treated with imatinib (Gleevec) or other drugs... The five year survival rate is ninety percent. $^{5}$

iv. Chronic lymphocytic leukemia (CLL): It never affects in children and Adults above the age of 55 are most commonly affected and most commonly seen in men rather women and the five year survival rate is $75 \%$. It is incurable. ${ }^{6}$

\section{Etiology}

Causes may vary with different leukemias, it may be due to by initiating oncogenes in the DNA and thereby disturbing the regulation of cell death, disparity. Somatic mutations which are present in the DNA are influenced by genetic factors and use of tobacco increases the risk of developing AML in adults. ${ }^{7}$

Chemicals like benzene and alkylating chemotherapeutic agents from previous malignancies human T-lymphotrophic virus, natural and artificial ionizing radiation are considered as some of the recognized causes for leukemia. ${ }^{8}$ Twin studies and family histories confirmed the genetic predisposition the affected persons may have a single gene or multiple genes is common factor. ${ }^{9}$ Diet has a very partial role.

\section{Signs and Symptoms}

Initially, normal bone marrow cells are replaced with more number of immature white blood cells which effects in a lack of blood platelets and these platelets helps in blood clotting mechanism. This will damage to the bone marrow. Excessive bleeding will be present and petechiae may developed and immune system of the children will be suppressed and they are more prone for infection leads to tonsillitis, soreness in the mouth, diarrhea, finally leads to anemia. Other symptoms like fever, chills, sweating in the night, and fatigued and weight loss will be present due to enlargement of liver and spleen. Headache may be present if the leukemic cells invade the central nervous system. ${ }^{10}$

\section{Diagnosis}

Following tests can be done to confirm diagnosis as they are:

I. Complete blood counts

II. Bone marrow examination

III. A lymph node biopsy

IV. Blood chemistry tests - to define the degree of liver and kidney damage

V. X-RAY - side effects on body parts as well as bones

VI. MRI - for the brain

VII. Ultrasound - for the kidneys, spleen and liver

VIII. CT scans - to check lymph nodes in the chest which is rarely used. ${ }^{11}$

\section{Treatment}

It is based on the type of leukemia and mainly treated with
a. Multidrug chemotherapy
b. Radiation
c. Bone marrow transplant. ${ }^{12}$

\section{Oral conditions}

From the disease and treatment point of view, Leukemic children suffer with many oral health problems which include mucositis, trismus, xerostomia, gingival bleeding, ulcerations, taste alteration, skin desquamation, and opportunistic infections, which further interferes inducing malnutrition. ${ }^{13}$

\section{Oral Complications Can Be Discussed As Follows}

\section{Primary complications}

Occur due to the disease itself, gingiva and bone is effected eg: leukemic gingival enlargement.

\section{Secondary complications}

Usually allied with direct effect of radiation or chemotherapy, eg: bleeding in the oral cavity, ulcers.

\section{Tertiary complications}

Due to a complex interplay of the therapy itself and its side effect, eg: mucositis, taste alteration, xerostomia

The following oral complications are most commonly seen children with ALL. ${ }^{14}$ 


\section{Saliva}

One of the side effects of radiotherapy in the head and neck region is xerostomia or reduced salivation and salivary changes takes place both quantitatively and qualitatively. Color of the saliva may be changed from transparent to opaque white or yellow this could be due to the an increase in viscosity and proportion of organic material in the saliva, salivary electrolyte levels will be altered, there by $\mathrm{pH}$ and buffering capacity of saliva decreases. Due to the radiation therapy, salivary acinar cells are degenerated followed by necrosis of salivary glands. Whenever there is a low $\mathrm{pH}$ of the saliva there is a shift in the oral microorganisms from Gram-positive to Gram-negative bacteria. ${ }^{15}$

Due to the viscous nature of the saliva children will have a difficulty in speech, chewing and swallowing, increased rate of dental caries more prone for gingival and periodontal diseases. Since there is decreased salivary secretion, taste buds function will be hindered further leads to alteration in the function of taste. Children does not show interest to have food followed by weight loss which further promotes nausea, vomiting finally it affects general health. ${ }^{16}$

Children with ALL, salivary calcium ions and phosphorous levels will be decreased. The treatment of Xerostomia is mouth should be rinsed with normal saline or cold sterile water as frequently as possible this will enhance the oral cavity clean and reduces the risk of infection. Artificial saliva based on carboxymethylcellulose and Pilocarpine, a cholinergic parasympathomimetic agent also can be used to improve the salivary flow rate. Additionally, topical fluoride application and scrupulous oral hygiene also play an important role to prevent further complications. ${ }^{17}$

\section{Dental Caries}

Changes in the salivary flow rate, viscosity and $\mathrm{pH}$ as well as prefer to take soft diet, shift of oral microflora and incapability to maintain oral hygiene all these factors contribute to the increased prevalence of dental carries in these children. ${ }^{18}$ Comparatively permanent dentition primary dentition was more prone for caries which was attributed to the use of sugar containing medications such as nystatin and also manual dexterity is not completely developed at that age. Sugar free oral rinses should be recommended in leukemic children. ${ }^{19}$

Most of the leukemic children suffering with inflammation of the oral mucosa which is induced by chemotherapy and they are not able to brush their teeth. The medical team should encourage gum massage as well as brush twice daily, regular dental check-ups. Children should not be allowed to sleep as soon as they take medication, fluoridated mouth rinses should be advised and application topical fluorides gives an added advantage..$^{20}$ Nowadays, remineralizing agents like CPP and ACP is available in the market and they have affinity to reverse the caries process. ${ }^{2}$

\section{Oral Mucositis}

It is an inflammation of the mucosa and it denotes all the signs of inflammation, most frequently seen in children with ALL., there will be dryness in the mouth, burning sensation, taste will be altered, difficulty in speech and eating. ${ }^{22-24}$ Initially erythema formation will be seen on the mucosa later white desquamating plaques are present which are painful, it bleeds when it touches. Later it is characterized by epithelial crusting and ulcer formation. ${ }^{25}$ The aggravated factors for mucositis could be sharp teeth or restorations etc. it is commonly seen in 5-7 days after cancer medication mucositis is commonly seen in young children. Buccal and labial mucosa, floor of the mouth, soft palate, oropharynx and the ventral and lateral surfaces of the tongue is. Is most frequently involved (16) Pain associated with mucositis may cause difficulty in eating, further leads to weight loss, anorexia, cachexia, and dehydration. The term mucosal barrier injury (MBI) is applicable for the above condition. ${ }^{26,16}$ As a result; the quality of life of a patient may be affected.

Chemotherapy along with administration of certain drugs like methotrexate and prednisone may impact the presence of oral lesions especially patients with ALL oral mucosal anomalies like shallow papillae, coated tongue, fetor oris, generalized ulcers, tender oral mucosa, and oral mucosal infections like candidiasis, herpes simplex, varicella/zoster, and cytomegalovirus are most common in patients with ALL. ${ }^{16,27-32}$

There are different treatment modalities to prevent mucositis during treatment. use of midline radiation blocks and 3-dimensional radiation treatment to the oral cavity can be used to treat Radiation induced mucosal injury, biological response modifiers such as Keratinocyte Growth Factor 1 (KGF-1), Keratinocyte Growth Factor 2 (KGF-2), Interleukin-11 and Transforming Growth Factor Beta-3 and Oral Cryotherapy (sucking ice chips) have been proved to be very effective in the treatment of oral mucositis. Apart from that Mucosal coating agents, water-soluble lubricating agents, artificial Saliva can be used. ${ }^{33,34}$ Additionally, Meticulous oral hygiene and symptomatic treatment for ulcers disposable sponge moistened in a diluted solution of baking soda and water can be used for debridement of necrotic tissue. Topical application of analgesic (i.e. benzydamine) and topical anesthetics (lidocaine) are also used to reduce pain. Anti bacterial mouthwash like a $12 \%$ chlorhexidine and sodium bicarbonate may be used to get a relief. ${ }^{35}$ Others like the bioadhesive agents such as hydroxypropyl cellulose may be useful improved healing. In case of severe mucositis supersoft tooth brushes are recommended, toothpaste with heavy flavoring agents should be avoided and in between uses brushes should be air-dried. ${ }^{36}$

Candida species especially Candida albicans is a normal commensal in the oral cavity of a healthy human beings. Children with ALL due to their immunocompromised condition, they become opportunistic pathogens which causes Candida infections seen particularly on the dorsum of the tongue and soft tissues. Candiasis causes two types of infections like... Acute pseudomembranous candidiasis, which has been referred to as thrush" traditionally shows a classical curdled milk appearance", pinpoint hemorrhagic areas are seen on the lesion when scraping. ${ }^{37}$

The other candida infection is Erythematous candidiasis classically manifests as diffuse erythematous areas in the oral cavity. The appearance produced is not only due to atrophy of the oral mucosa but also due to an increased vascularization. Clinically, acute pseudomembranous candidiasis progress into erythematous candidiasis often it may also be manifested as angular cheilitis. ${ }^{38}$

To manage candidiasis topical and systemic antifungal agents are administered and most commonly used topical antifungal agents are nystanin, clotrimazole, and ketoconazole.

Systemic agents such as fluconazole, itraconazole, and ketoconazole are prescribed in severe cases. Whenever the immune system of the patient is improved the candida infection is suppressed. The viral infections seen in children with leukemia are herpes simplex, varicella zoster, cytomegalovirus, adenovirus, and Epstein barr virus, management is palliative mainly, aimed at pain control and supportive care. $^{39}$

The drugs which are used to treat leukemia will have deleterious effects on the crown as well as roots of the teeth. There will be hypomineralization or hypomaturation of the Enamel and dentin 
formation which leads to deformed and discolored crowns of the teeth and roots of the teeth will be short, thin and tapered and appreciated in the radiographs. ${ }^{40}$ Other changes include agenesis, enlarged pulp chambers hypoplasia, microdontia, supernumerary teeth, and taurodontism ${ }^{41}$ however, aforementioned features were more predominant in children with ALL. Hypoplasia of the jaws leads to malocclusion as a result of direct radiation of the head and neck region. ${ }^{42-46}$ Other side effects of radiation includes Irradiation to the central nervous system may reduce hypothalamic pituitary function will be reduced, subsequently production of growth hormone and thyroid stimulation hormone will be diminished. This may, in turn, adversely affect the development of craniofacial complex. ${ }^{47-49}$

Taste alteration is also called as dysfuesia which is one of the side effects of radiation therapy in the oral cavity. Normally, the taste buds situated in the posterior part of the tongue but in leukemic children saliva will be highly viscous and the rate of salivary secretion will be less hence, the eatables do not reach the taste buds further leads to alteration of the taste especially bitter and sour tastes. It is a temporary state after 2 months -12 months again the taste buds will be regenerated by myelosuppresive therapy. The management of taste alteration is supplementation of Zinc which is available as a zinc sulfate $220 \mathrm{mg}$ twice a day for two weeks. ${ }^{50-52}$

Trismus or limited mouth opening is most commonly seen after administration of chemotherapeutic agents. Trismus is due the muscular fibrosis, edema and cellular destruction. The muscles which are involved in opening and closing of the mouth will develop fibrosis further leads to limited mouth opening and later pain in the Temporo Mandibular Joint (TMJ). Is hampers the oral health of the patient. Management of trismus is exercises to stimulate mouth opening and closing, administration of anti-inflammatory medication, and muscle relaxants. 55 and TMJ appliances are used for the treatment TMJ disorders. $^{51}$

Oral complications of radiotherapy for the head and neck region is Osteoradionecrosis of the mandible which has relatively poor blood vascularization and due to the radiation there will be damage to the endothelial linings of the vessels leads to the hypocellularity and bone is more prone for fracture which is pathological. Management of Osteoradionecrosis is Hyperbaric oxygen therapy (HBO), recommended dose is 20 to 30 dives of $\mathrm{HBO}$ at $100 \%$.

Oxygen is usually prescribed at 2 to 2 atmospheres of pressure, the mechanism of action is it increases oxygenation of the tissue, stimulates angiogenesis, and improves osteoblast formation and also function of the fibroblast. ${ }^{53}$

Generalized Gingival hyperplasia is most prevalent finding of the gingiva in leukemic children. Clinically, there will be involvement of marginal gingiva, attached gingiva and interdental papillae, when it is severe, all the crowns of the teeth may be covered with gingival hyperplasia. The signs of inflammation like color may vary from pale red to deep purple, loss of stippling and gingiva seems to be swollen. Bleeding will be present during brushing. The treatment of Gingival hyperplasia is gentle brushing twice a day and massaging of the gums with wet finger can improve the condition. Antiseptic mouthwashes like povidone iodine solution (betadine) and topical styptics are also used in gingival bleeding. ${ }^{54-57}$

\section{Dental treatment}

In case of any dental emergency, the oncologist and hematologist should consult with the dental surgeon, all the minor procedures should be executed at a platelet count of $40,000 / \mathrm{mm} 3-50,000 / \mathrm{mm} 3$, whereas for major surgeries, it is appropriate that the platelet count is at a minimum level of $100,000 / \mathrm{mm} 3$. According to the norms of the American Heart Association a prophylactic antibiotic coverage should be given.

\section{Extractions}

Any oral surgery, however minor, must be done in hospital under the care of the physician in charge and in consultation with the haematologist. While the actual removal of the teeth creates no difficulties, the haemorrhage potential is high and scrupulous after care to prevent infection must be observed. The type of anesthetic to be used must be decided after all aspects of the particular case have been considered. Deep injections such as an inferior alveolar nerve block should never be used because of the dangers of deep haemorrhage, but a superficial injection may be permissible. Some type of general anesthetic may be a method of choice. The problem associated with corticosteroid therapy should not be overlooked..$^{58}$

\section{Conservation}

Apart from the avoidance of injections, conservation presents no special problems. The teeth should be free from sepsis and, attention of a filling which seals the cavity. If necessary, ideals of extension and good cavity form must be sacrificed. Treatment should be as short as reasonable and as pleasant as possible. ${ }^{59}$

\section{Periodontal Care}

Treatment of acute oral infections should be referred to the physician in charge who will decide the therapy to be used. Patients who are having ant leukemic therapy do not usually present any special chronic periodontal problem but should nevertheless have instruction in tooth brushing to keep the gingivae healthy.

\section{Orthodontics}

Only if the patient himself is very anxious for treatment of a malocclusion should it be considered, and then mainly from the psychological aspect. Though expectancy of life is short, it maybe justifiable to do applicable therapy, and in such a case it should be as brief and as simple as possible, and planned mostly for immediate aesthetic effect. ${ }^{60}$

\section{Conclusion}

Complete evaluation and diagnosis is important to commencing treatment. Depending on the severity it may be important to consider alternative treatment. The extension of the life expectancy of leukemic patients by modern chemotherapy has now brought them into the category of those who need supportive and preventive dental care. The two major chemical problems of infection and haemorrhage which can cause a fatal termination could stem from dental neglect and efforts to keep the mouth healthy can prolong life. The first need is to eliminate sepsis, and then to maintain the mouth in a fit state to prolong life.

\section{Acknowledgments}

None.

\section{Conflicts of Interset}

None.

\section{References}

1. Genc A, Atalay T, Gedikoglu G, et al. Leukemic children: Clinical and histopathological gingival lesions. $J$ Clin Pediatr Dent. 1998;22(3):253-256. 
2. Arora RS, Eden TO, Kapoor G. Epidemiology of childhood cancer in India. Indian J Cancer. 2009;46(4):264-273.

3. Mthers CD, Cynthia BP, Alan DL, et al. Cancer incidence, mortality and survival by site for 14 regions of the world. Global Programme on Evidence for Health Policy Discussion Paper no.13 (World Health Organisation). 2001.

4. Finding Cancer Statistics-Cancer Stat Fact Sheets Chronic Lymphatic Leukemia National Cancer Institute.

5. Jameson JN, Kasper DL, Randolph HT, et al. Harrison's principles of internal medicine. McGraw-Hill Medical Publishing Division, New York, USA. 2005.

6. Clovin GA, Elfenbein GJ. The latest treatment advances for acute myelogenous leukemia. Med Health RI. 2003; 86(8):243-246.

7. Ross JA, Kasam CM, Davis SM, et al. Diet and risk of leukemia in the Iowa Woman's Health Study. Cancer Epidemiol Biomarkers Prev. 2002;11(8):777-781.

8. Wiernik PH. Adult leukemias. BC Decker, New York, USA. 2001. p. $3-15$.

9. Greenberg MS, Glick M, Skip JA. Burket's Oral Medicine. (11th edn), BC Decker, Hamilton, USA. 2008. p. 79-84.

10. Nikoui M, Lalonde B. Oro-dental manifestations of leukemia in children. J Can Den Assoc. 1996;62(5):443-446.

11. Vinkier F, Declerck D. Oral manifestations in leukemic children and their diagnostic value. Acta Stomatol Belg. 1989;86(3):219-226.

12. Ilgenli T, Oren H, Uysal K. The acute effects of chemotherapy on the oral cavity. Prevention and management. Turkish J Cancer. 2001;31(3):93-105.

13. Mathur VP, Dhillon JK, Kalra G. Oral health in children with leukemia. Indian J Palliat Care. 2001;18(1):12-18.

14. Akyol H, Uysal KM, Ören H. The incidence of oral complications in pediatric patients receiving high dose chemotherapy. Med Ped Oncol. 1997;29:442.

15. Emidio TC, Maeda YC, Caldo-Teixeira AS, et al. Oral manifestations of leukemia and antineoplastic treatment - a literature review (part II). Braz J Health. 2010;1:136-144.

16. Peterson DE. Research advances in oral mucositis. Curr Opin Oncol. 1999;11(4):261-266.

17. Azher U, Shiggaon N. Oral health status of children with acute lymphoblastic leukemia undergoing chemotherapy. Indian J Dent Res. 2013;24(4):523.

18. Maciel JC, de Castro CG Jr, Brunetto AL, et al. Oral health and dental anomalies in patients treated for leukemia in childhood and adolescence. Pediatr Blood Cancer. 2009;53(3):361-365.

19. Kinirons MJ, Fleming P, Boyd D. Dental caries experience of children in remission from acute lymphoblastic leukaemia in relation to the duration of treatment and the period of time in remission. Int $J$ Paediatr Dent. 1995;5(3):169-172.

20. Epstein JB, Vickars L, Spinelli J, et al. Efficacy of chlorhexidine and nystatin rinses in prevention of oral complications in leukemia and bone marrow transplantation. Oral Surg Oral Med Oral Pathol. 1992;73(6):682-689.

21. Kusumakumary P, Sankaranarayanan R, Padmakumary G, et al Childhood cancer in Kerala, India. Lancet. 1991;338(8764):455-456.

22. Runge ME, Edwards DL. Orthodontic treatment for an adolescent with a history of acute lymphoblastic leukemia. Pediatr Dent. 2010;22(6):494-498.
23. Lino MD, Carvalho FB, Oliveira LR, et al. Laser phototherapy as a treatment for radiotherapy induced oral mucositis. Braz Dent J. 2011;22(2):162-165

24. Lima AG, Antequera R, Peres MP, et al. Efficacy of low-level laser therapy and aluminum hydroxide in patients with chemotherapy and radiotherapy-induced oral mucositis. Braz Dent J. 2010;21(3):186-192.

25. Sonis ST. Mucositis: The impact, biology and therapeutic opportunities of oral mucositis. Oral Oncol. 2009;45(12):1015-1020.

26. Parulekar W, Mackenzie R, Bjarnason G, et al. Scoring oral mucositis Oral Oncol. 1998;34(1):63-71.

27. Pels E. Oral hygiene status and selected saliva biomarkers in children with acute lymphoblastic leukemia during anticancer therapy. J Leuk. $2013 ; 1: 115$.

28. Williams MC, Lee GT. Childhood leukemia and dental considerations. $J$ Clin Pediatr Dent. 1961;15:160-164

29. Levy Polack MP, Sebelli P, Polack NL. Incidence of oral complications and application of a preventive protocol in children with acute leukemia. Spec Care Dentist. 1998;18(5):189-193.

30. Sepúlveda E, Brethauer U, Rojas J, et al. Oral ulcers in children under chemotherapy: Clinical characteristic and their relation with Herpes Simplex Virus type 1 and Candida albicans. Med Oral Patol Oral Cir Bucal. 2009;10(Suppl 1):1-8.

31. da Fonseca MA. Dental care of the pediatric cancer patient. Pediatr Dent. 2009;26(1):53-57.

32. Anirudhan D, Bakhshi S, Xess I, et al. Etiology and outcome of oral mucosal lesions in children on chemotherapy for acute lymphoblastic leukemia. Indian Pediatr. 2008;45(1):47-51.

33. Kumar S, Balan A, Sankar A, et al. Radiation induced oral mucositis Indian J Palliat Care. 2009;15(2):95-102.

34. Keefe DM, Schubert MM, Elting LS, et al. Updated clinical practice guidelines for the prevention and treatment of mucositis. Cancer. 2007;109(5):820-831.

35. Best practice guidelines for the management of oral complications from cancer therapy. Cancer Care Nova Scotia.

36. Wright JR, McKenzie M, DeAngelis C, et al. Radiation induced mucositis: Co-ordinating a reserach agenda. Clin Oncol. 2003;15(8):473-477.

37. Javed F, Klingspor L, Sundin U, et al. Periodontal conditions, oral Candida albicans and salivary proteins in type 2 diabetic subjects with emphasis on gender. BMC Oral Health. 2009;9:12.

38. Scully C. Oral and Maxillofacial Medicine: The Basis of Diagnosis and Treatment. ( $4^{\text {th }}$ edn), Elsevier Science Limited, London. 2007. p. 252-268

39. Pui CH, Campana D, Evans WE. Childhood acute lymphoblastic leukemia - Current status and future perspectives. Lancet Oncol. 2001;2(10):597-607.

40. Dahllöf G, Rozell B, Forsberg CM, et al. Histologic changes in dental morphology induced by high dose chemotherapy and total body irradiation. Oral Surg Oral Med Oral Pathol. 1994;77(1):56-60.

41. Goho C. Chemoradiation therapy: Effect on dental development. Pediatr Dent. 1993;15(1):6-12.

42. Vahlsing HL, Kim SK, Feringa ER. Cyclophosphamide-induced abnormalities in the incisors of the rat. J Dent Res. 1977;56(7):809-816.

43. Stene T. Effect of vincristine on odontoblasts in rat incisor. Scand J Dent Res. 1978;86(5):346-356.

44. Goodman ED, Fuks AB. The effects of anti-leukemic therapy on the developing dentition: case report. Pediatr Dent. 1985;7(4):318-321. 
45. Dahllöf G, Rozell B, Forsberg CM, et al. Histologic changes in dental morphology induced by high dose chemotherapy and total body irradiation. Oral Surg Oral Med Oral Pathol. 1994;77(1):56-60.

46. Xavier AM, Hegde AM. Preventive protocols and oral management in childhood leukemia - the pediatric specialist's role. Asian Pac J Cancer Prev. 2010;11(1):39-43.

47. Mladosievicova B, Jurkovic R, IzakovicovaHolla L. Dental abnormalities after treatment for childhood cancer. Klin Onkol. 2015;28(1):20-23.

48. Jaffe N, Toth BB, Hoar RE, et al. Dental and maxillofacial abnormalities in long-term survivors of childhood cancer: Effects of treatment with chemotherapy and radiation to the head and neck. Pediatrics. 1984;73(6):816-823.

49. Rosenberg SW, Kolodney H, Wong GY, et al. Altered dental roo development in long-term survivors of pediatric acute lymphoblastic leukemia. A review of 17 cases. Cancer. 1987;59(9):1640-1648.

50. Subramaniam P, Babu KL, Nagarathna J. Oral manifestations in acute lymphoblastic leukemic children under chemotherapy. J Clin Pediatr Dent. 2008;32(4):319-324.

51. Costa EM, Fernandes MZ, Quinder LB, et al. Evaluation of an oral preventive protocol in children with acute lymphoblastic leukemia. Pesqui Odontol Bras. 2003;17:147-150.

52. Milins B, Martin MV, Williams MC. Raised salivary endotoxin concentration as a predictor of infection in pediatric leukemia patients. Oral Surg Oral Med Oral Pathol Oral Radiol Endod. 2008;88(1):50-55.
53. Grimaldi N, Sarmento V, Provedel L. Dental care in prevention and treatment of osteoradionecrosis. Literature review Rev Bras Cancerol. 2005;51:319-324

54. Sheehy EC, Beighton D, Roberts GJ. The oral microbiota of children undergoing liver transplantation. Oral Microbiol Immunol. 2000;15(3):203-210.

55. McKenna SJ. Leukemia. Oral Surg Oral Med Oral Pathol Oral Radiol Endod. 2000;89(2):137-139.

56. Uderzo C, Fraschini D, Balduzzi A, et al. Long-term effects of bone marrow transplantation on dental status in children with leukaemia. Bone Marrow Transplant. 1997;20(10):865-869.

57. Karolewska E, Konopka T, Pupek M, et al. Mucositis in children with Leukemia and salivary defense factors. Dent Med Probl. 2007;44:30-36.

58. Herrstedt J. Prevention and management of mucositis in patients with cancer. Int J Antimicrob Agents. 2000;16(1):161-163.

59. Karolewska E, Konopka T. Preventive-therapeutic dental care protocol in children with leukemia. Czas Stomatol. 2006;59:245-252.

60. Acute lymphoblastic leukemia in children. Oral and Craniofacial complications of all treatment. Pediatric dental health. 